\title{
Um projeto socioeducativo com crianças e jovens do Lar da Menina
}

\section{Ana Sara Castaman ${ }^{1}$, Andréia Paula Franceschi Machado²}

Resumo: O fortalecimento de laços e vínculos possui caráter preventivo, pautado na defesa dos direitos e no desenvolvimento das capacidades e potencialidades de cada indivíduo, bem como precavendo situações de vulnerabilidade. Logo, uma das tarefas relevantes dos projetos socioeducativos é permitir aos participantes condições para que possam se assumir enquanto seres sociais, críticos, históricos, pensantes e transformadores. Assim, este ensaio tem por finalidade apresentar o projeto socioeducativo de extensão desenvolvido com as crianças e adolescentes em vulnerabilidade social na Ação Social Getuliense Nossa Senhora da Salete - Lar da Menina, em Getúlio Vargas/RS. Realizaram-se oficinas (rodas de conversa, atividades práticas e lúdicas, dinâmicas, esportes) voltadas para a socialização, o diálogo, a conscientização, a prevenção, o desenvolvimento da autonomia, a escuta, o acolhimento, a complementação de ações da família e da comunidade na proteção e desenvolvimento das crianças e adolescentes, a ampliação do universo informacional, entre outros. Apresenta-se a experiência e a contribuição das ações socioeducativas para a autonomia do sujeito e o fortalecimento de laços e vínculos. Conclui-se que o projeto socioeducativo tem contribuído para a formação de seus participantes enquanto seres autônomos e críticos, bem como tem fortalecidos os laços e vínculos.

Palavras-chave: Organizações Não-Governamentais; Socioeducativo; Vínculos Sociais; Autonomia

\section{Socio-educational project with child and young people in the 'Lar da Menina' House}

Abstract: The strengthening of social ties and bonds has a preventive character, based on the human rights defense, and the development of the individual potential capacities, as well as to prevent situations of vulnerability. Therefore, one of the relevant tasks of socio-educational projects is to provide participants with conditions so that they can come out as social, critical, historical, thinking, and transforming beings. Thus, this essay aims to present the socio-educational extension project developed with children and adolescents in social vulnerability at the "Ação Getuliense Nossa Senhora da Salete - Lar da Menina", in Getúlio Vargas, Rio Grande do Sul State, Brazil. Workshops (conversation circles, practical and playful activities, dynamics, sports) were held aimed at socialization, dialogue, awareness, prevention, development of autonomy, listening, welcoming, complementing family actions and community in the protection and development of children and adolescents, expansion of the informational universe, among others. The experience and the contributions of the socio-educational actions for the subject's autonomy and strengthening bonds are presented. It is concluded that the socioeducational project contributed to the formation of its participants as autonomous and critical beings, as well as strengthening social ties and bonds.

Keywords: Non-Governmental Organizations; Socio-educative; Social Ties; Autonomy

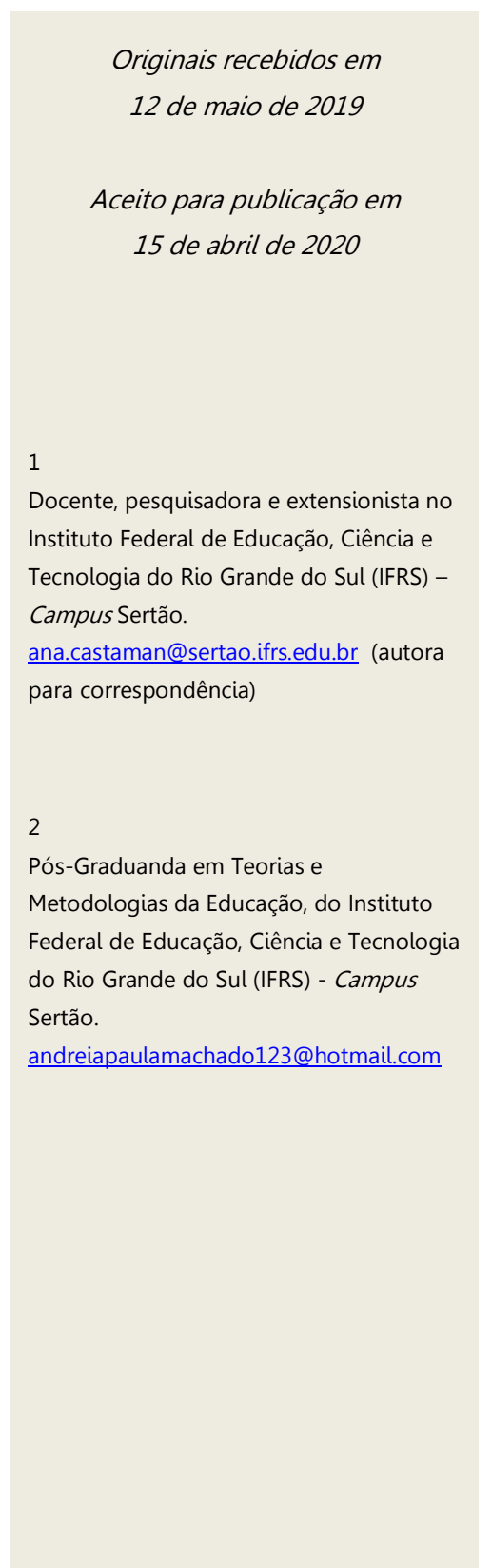




\section{Introdução}

Projetos socioeducativos são propostas desenvolvidas com determinados grupos de faixas etárias diferenciadas, os quais possibilitam contribuir para o bem-estar e também para o aprendizado daqueles que o frequentam. Dito de outro modo, constituem-se como iniciativas individuais ou coletivas que têm por finalidade proporcionar a melhoria da qualidade de vida de pessoas e comunidades.

As ações socioeducativas conectam a educação e a proteção social, ao atender crianças e adolescentes, com a oferta de atividades lúdicas, artísticas e esportivas, e são realizadas em parceria com o governo municipal, estadual ou federal. Grande parte dessas práticas contemplam o público que se encontra em situação de vulnerabilidade social (Carvalho \& Azevedo, 2005).

Um projeto (social) nasce de uma ideia de um desejo ou interesse de realizar algo, ideia que toma forma, se estrutura e se expressa através de um esquema (lógico), o qual, no entanto, é apenas esboço(sempre) provisório, já que sua implementação exige constante aprendizado e reformulação (Armani, 2004, p. 18).

Esses projetos são construções sociais que se solidificam dia a dia, já que dedicam esforços para otimizar ou amenizar uma determinada circunstância, lidando com ideias e aspirações individuais e coletivas, voltadas para a construção do bem-estar comum. Stephanou (2003, p. 11) apresenta a concepção de projetos sociais:

Os projetos sociais nascem do desejo de mudar uma realidade. Os projetos são pontes entre o desejo e a realidade. São ações estruturadas e intencionais, de um grupo ou organização social, que partem da reflexão e do diagnóstico sobre uma determinada problemática e buscam contribuir, em alguma medida, para 'um outro mundo possível'.

Neste contexto, o projeto de extensão socioeducativo desenvolvido na Entidade Ação Social Getuliense Nossa Senhora da Salete - Lar da Menina (ONG Filantrópica que atende crianças da educação infantil e do Programa de Apoio Socioeducativo em Meio Aberto), em parceria com o Instituto Federal de Educação, Ciência e Tecnologia do Rio Grande do Sul (IFRS) - Campus Sertão, permite aos usuários do Serviço de Convivência e Fortalecimento de Vínculos uma conciliação entre educação e relações interpessoais. Estas ações socioeducativas extensionistas facilitam o aprendizado, desenvolvendo a capacidade de atuar em trabalhos de grupos e, por sua vez, uma vida familiar e comunitária ancorada no respeito e na ajuda mútua.

Levando em consideração a importância de abordar a questão socioeducativa com crianças e adolescentes, este artigo de abordagem qualitativa, pautado em um referencial teórico que se ocupa com a temática socioeducativa, e elaborado a partir da análise de experiência em um projeto socioeducativo de extensão, está dividido em três partes: a) alude a conceitos e fundamentos acerca de uma Organização Não-Governamental, além de apresentar o projeto de extensão realizado no Lar da Menina; b) trata das contribuições do projeto socioeducativo para a autonomia do sujeito; c) reforça a importância do projeto socioeducativo no fortalecimento de laços e vínculos dos participantes.

\section{Organização Não-Governamental: Caso Lar Da Menina}

De acordo com Landim (1998), o termo Organizações Não-Governamentais (ONG) foi empregado na década de 1940, pela Organização das Nações Unidas (ONU), para designar diferentes entidades executoras de projetos humanitários ou de interesse público. Constituem-se como organizações, sem fins lucrativos, elaboradas por pessoas que atuam voluntariamente em defesa de uma causa, tais como: proteção do meio ambiente, defesa dos direitos humanos, erradicação do trabalho infantil, entre outros. 
No Brasil são qualificadas como Organizações da Sociedade Civil de Interesse Público ou Entidades de Utilidade Pública. A terminologia também é utilizada como análoga ao Terceiro Setor, embora seja apenas um dos atores que compõem esse campo. Landim (2002, p. 216) explica a respeito dessas controvérsias polissêmicas:

Organização não governamental é expressão que traz a marca da polissemia, movendo-se num campo que se presta a várias apropriações ideológicas ou discursivas, possibilitando usos diversificados por diferentes atores - e, portanto, podendo constituir-se em objeto de polêmica e luta em torno desses usos.

Nos anos 1990, disseminaram-se no Brasil as ONG assistenciais, fruto de políticas sociais e como complementares das metas públicas. As ONG, conforme elucida Silveira (2006), surgiram para suprir demandas que não eram atendidas de modo satisfatório pelo Estado. Muitos investidores sociais doavam recursos para governos de países subdesenvolvidos, e percebiam que tais quantias não eram revertidas em bens públicos, por inúmeros motivos.

Nesse cenário, as ONG prosperaram e proliferaram como organizações competentes e exemplares, com as quais filantropos, governos e outras instituições podiam contar. No Brasil, sua atuação se dá em diversas categorias, como: educação; saúde; comunidade; apoio à criança e ao adolescente; voluntariado; meio ambiente; apoio a pessoas com deficiências; parcerias com o governo; entre outros segmentos. Esses exemplos denotam a amplitude e a abrangência das ações empreendidas por essas organizações, em que fazem parte mais de 540 mil entidades registradas no Terceiro Setor mundial (Tachizawa, 2004).

Tendo em vista a relevância de fomentar este tipo de atividade filantrópica, a Entidade Ação Social Getuliense Nossa Senhora da Salete - Lar da Menina (ONG que atende crianças de educação infantil e do Programa de Apoio Socioeducativo em Meio Aberto), dedica-se a proporcionar uma nova visão de vida comunitária e familiar para as crianças e os adolescentes em estado de vulnerabilidade social, participantes dos projetos do Serviço de Convivência e Fortalecimento de Vínculos (Lar da Menina, 2019). Entende-se assim que, a partir da caridade cristã é que se pôde avançar em direção ao entendimento da filantropia:

A filantropia pode ser entendida, grosso modo, como a laicização da caridade cristã, ocorrida a partir do século XVIII, e que teve nos filósofos das luzes seus maiores propagandistas. O fazer o bem, o socorro aos necessitados, deixa de ser uma virtude cristã para ser uma virtude social [...] (Sanglard, 2003, p. 1095).

A Ação Social Getuliense Nossa Senhora da Salete - Lar da Menina foi fundada no ano de 1967. O Lar da Menina foi fundado inicialmente para ser um orfanato para meninas. Mantém-se há 53 anos no município de Getúlio Vargas/RS com recursos oriundos de projetos contemplados pelas esferas dos governos municipal, estadual, federal, e também de empresas privadas. A prefeitura municipal assegura um convênio pelo qual repassa uma subvenção mensal, que auxilia no pagamento dos recursos humanos. Ainda, a entidade mantém um 'brechó' de roupas e artigos de cama, mesa e banho, doados por uma entidade assistencial da Alemanha (Lar da Menina, 2019).

O Lar da Menina é uma ONG que oferece duas modalidades de atendimento: Escola de Educação Infantil Favinhos de Mel em turno integral atendendo crianças de 0 a 5 anos de idade, e o Programa de Apoio Socioeducativo em Meio Aberto (ASEMA), no contraturno escolar, para crianças de 6 a 12 anos de idade. $O$ ASEMA é um programa de proteção estabelecido pelo Estatuto da Criança e do Adolescente, em seu artigo 90 (Lar da Menina, 2019). 
A construção da Proposta Político-Pedagógica (PPP) da entidade justificou-se pela necessidade, entre muitas, de estimular o envolvimento de todos os segmentos e níveis da instituição. A referida PPP apresenta como objetivo principal "oportunizar para as crianças que frequentam a entidade um espaço de desenvolvimento integral norteado por valores e convivência coletiva, respeitando-se cada individualidade, na busca da construção de cidadãos conscientes e sedentos por qualidade de vida" (Lar da Menina, 2019). Para tanto, há uma série de oficinas, tais como: artes, esportes, contação de histórias, música, que têm por finalidade a concretização dos princípios e finalidades do Lar. As atividades desenvolvidas no Lar pelos colaboradores são voltadas para a socialização e vivências familiares e comunitárias, objetivando manter o bom relacionamento individual e coletivo. Trabalha-se também a construção do ser social, as dificuldades e as potencialidades de cada indivíduo, bem como o autocontrole e a realização de trabalhos em grupo.

Diante do exposto e como uma forma de agregar às ações socioeducativas já desenvolvidos no Lar, no ano de 2015, em parceria com o Instituto Federal de Educação, Ciência e Tecnologia do Rio Grande do Sul (IFRS) Campus Sertão, iniciou-se o Projeto de Extensão, atualmente intitulado "Práticas educativas: fortalecimento de laços afetivos entre os usuários participantes do Lar da Menina de Getúlio Vargas". O objetivo do referido projeto é aplicar práticas educativas por meio de oficinas, de modo a favorecer o desenvolvimento da autonomia, de sociabilidades, de fortalecimento de vínculos sociais e familiares, e prevenir situações de vulnerabilidades e risco social dos usuários participantes do Lar da Menina (Castaman, 2019).

O projeto de extensão socioeducativo está sendo desenvolvido por duas servidoras do IFRS - uma coordenadora (Bacharel e Licenciada em Psicologia e Pedagogia, Doutora em Educação), e uma colaboradora (Bacharel em Agronomia, Licenciada em Ciências Biológicas e Especialista em Gestão Pública) - e também por duas bolsistas/estudantes (uma graduada em Ciências Biológicas e matriculada no curso de Formação Pedagógica para Graduados não Licenciados; e outra licenciada em Matemática, graduada em Administração, matriculada nos cursos de Formação Pedagógica para Graduados não Licenciados e de Pós-Graduação Lato Sensu em Teorias e Metodologias da Educação) que atuam 8h semanais cada, com crianças e adolescentes com algum quadro de vulnerabilidade social.

A ação extensionista consolida-se na ONG por meio de oficinas pedagógicas diversas com 45 crianças divididas em três grupos, conforme a faixa etária, e 15 adolescentes em um único grupo, sendo que os participantes desenvolvem suas atividades na entidade em horário inverso ao turno escolar. As temáticas abordadas nas oficinas pedagógicas são sugeridas pela equipe gestora do Lar e, a partir da formação inicial e continuada dos integrantes do projeto são planejadas as ações de intervenção. Destaca-se que todo o planejamento educacional e a execução das atividades (efeitos e potenciais benefícios) são acompanhadas e avaliadas em reuniões mensais que se realizam sob responsabilidade de tal equipe. Ainda, os usuários/participantes são acompanhados por uma equipe de apoio (psicólogo, assistente social e pedagogo) que verifica a percepção dos mesmos em relação à instituição e às ações ali desenvolvidas.

As oficinas implementadas permitem estabelecer relações sociais positivas, de forma a contribuir para o fortalecimento de laços e de vínculos, e também para o processo de autonomia do sujeito. Para tanto, inicialmente visa-se a conhecer a história dos participantes e, na sequência, são aplicadas as atividades que têm o intuito de promover o sentimento de pertencimento e de identidade, fortalecendo vínculos familiares e incentivando a socialização e a convivência comunitária. Ainda, prioriza-se o acolhimento, o carinho e a socialização, para que estas crianças e adolescentes possam desenvolver relações interpessoais com a comunidade. Assim, na próxima seção serão apresentadas as ações socioeducativas extensionistas desenvolvidas por meio do Projeto "Práticas educativas: fortalecimento de laços afetivos entre os usuários participantes do Lar da Menina de Getúlio Vargas" e as contribuições do mesmo para a autonomia pessoal. 


\section{Projeto socioeducativo: contribuições para a autonomia do sujeito}

Segundo Costa (2006), a socioeducação decorre de um pressuposto básico de que o desenvolvimento humano deve ocorrer de forma integral, contemplando as múltiplas dimensões do ser humano. A opção por uma educação que vai além da escolar e profissional está intimamente ligada a uma nova forma de se pensar e de abordar o trabalho com o adolescente.

A unidade educativa deve ser capaz de oferecer um leque, um cardápio, uma pluralidade de modalidades educativas ao educando, que lhe possibilite desenvolver sua autonomia (capacidade de decidir segundo suas crenças, valores, pontos de vista e interesses); sua solidariedade (capacidade de atuar como solução e não como problema em questões relativas ao bem comum); sua competência (desenvolvimento de competências pessoais, relacionais, produtivas e cognitivas) (Costa, 2006, p. 67).

Para Carvalho et al. (2003), os projetos sociais permitem uma reflexão sobre determinado problema, e contribuem, por meio de ações organizadas, para possíveis atualizações ou mudanças. Os projetos socioeducativos que se desenvolvem a partir de suas ações têm por finalidade contribuir para a transformação de uma determinada realidade social, auxiliando no relacionamento intrapessoal e interpessoal entre crianças e adolescentes com o ambiente em que convivem.

Quando se trata da questão da vulnerabilidade social, sabe-se que existe o envolvimento de vários elementos norteadores neste processo, como: comportamento, hábitos, maneira de pensar, modo de vida, relacionamentos familiares e comunitários, entre outros, os quais podem desencadear inúmeros problemas, quando não for trabalhado o autocontrole e a autonomia. Para isso existem os projetos socioeducativos, que buscam suprir lacunas existentes na formação humana, fazendo com que os mesmos desenvolvam, em especial, a autonomia.

A dimensão de autonomia é entendida como uma capacidade de lidar com sua rede de dependências, de eleger objetivos e crenças, atribuir-lhes valor com discernimento e colocá-los em prática com a participação e apoio de outros. Assim, autonomia é sempre uma dimensão relativa e depende do acesso dos sujeitos à informação, de sua capacidade de utilizar esse conhecimento em exercício crítico de interpretação. Dito de outra forma, autonomia pode ser expressa pela maior capacidade dos sujeitos de compreenderem e agirem sobre si mesmos e sobre o contexto, conforme objetivos democraticamente estabelecidos (Campos \& Campos, 2006, p. 670).

A experiência da produção coletiva é sinônimo de autonomia interdependente. E é nesse ambiente que a discussão e a formulação de uma concepção de convivência e fortalecimento de vínculos anuncia-se e ganha sentido de pertinência (Secretaria Nacional de Assistência Social, 2017). Freire (2002) ressalta que é no processo coletivo, em mutualidade, que se aprendem diferentes saberes igualmente importantes. $O$ autor faz ainda uma transposição do campo educativo para o trabalho social, sustentando a possibilidade de reconhecer o mesmo valor para os conhecimentos acadêmicos e para a experiência vivida, quando ambos são colocados diante da finalidade do aprendizado e da proteção do cidadão. Desse modo, é preciso admitir que, nas relações educativas e de proteção social, usuários e profissionais são sujeitos de conhecimentos e de direitos.

Uma das tarefas mais importantes da prática educativa-crítica é propiciar as condições em que os educandos em suas relações uns com os outros e todos com o professor ou professora ensaiam a experiência profunda de assumir-se. Assumir-se como ser social e histórico como ser pensante, comunicante, transformador, criador, realizador de sonhos, capaz de ter raiva porque capaz de amar. [...] A assunção de nós mesmos não significa a exclusão dos outros. É a 'outredade' do 'não eu', do tu, que me faz assumir a radicalidade de meu eu (Freire, 2002, p. 41). 
Diante dessa perspectiva, durante a execução do projeto de extensão foi desenvolvido um conjunto de atividades socioeducativas, com o objetivo de promover a autonomia dos participantes. Contudo, destacamse dois métodos: a dramatização e o Stop.

A técnica da dramatização consiste na encenação de um problema ou situação na área das relações humanas, por duas ou mais pessoas. Nessa cena hipotética os papéis são experienciados tais como na realidade. A síntese dessas atribuições é um dos aspectos mais relevantes na encenação. Aqueles que participam da encenação devem compreender o tipo de pessoa que necessitam interpretar durante a dramatização. $O$ resumo do papel deve conter apenas a condição emocional e as atitudes a serem adotadas, sem detalhes sobre aquilo que deverá ocorrer durante a apresentação. Essa técnica possibilita a informalidade e assegura a participação psicológica do indivíduo e do grupo; elimina as inibições e facilita a comunicação (Portal da Educação, s. d).

A estratégia é útil para o desenvolvimento da capacidade de relacionamento com outras pessoas por meio do entendimento da natureza do comportamento humano; fornecimento de dados de relações humanas que possam ser utilizados para análise e discussão; desenvolvimento da autonomia; facilitação da comunicação; oportunização de situações para que os indivíduos 'representem' seus problemas pessoais; e criação, no grupo, de uma atmosfera de experimentação e de possível criatividade (Portal da Educação, s. d.). Prieto (2007) reforça que a dramatização promove a autonomia com o envolvimento do estudante na sua própria aprendizagem, fomentando a confiança em si mesmo, impulsionando a desinibição e a fluidez verbal.

A outra técnica a ser apresentada chama-se Stop. Tem por finalidade oportunizar ao indivíduo que conheça a si mesmo e aos demais, favorecendo a criatividade, a rapidez de raciocínio, a comunicação interpessoal e ao diálogo. Assim, ao ser dado o início ao jogo, cada um deve responder ao maior número de perguntas possíveis, de acordo com as categorias/temáticas escolhidas. As categorias são escolhidas conforme a idade e podem corresponder a: fruta, objeto, animal, filme, flor, cor, nome pessoal, localidade, carro, corpo humano, comportamentos, etc. Ou seja, os conteúdos podem ser definidos pelo grupo.

As tabelas podem ser construídas em folha de papel. Para iniciar cada rodada é necessário o sorteio da letra predominante. Para cada tema, os participantes devem encontrar um termo que comece com a letra sorteada. Assim, na sequência, os participantes deverão escrever, na tabela, abaixo de cada tema, uma palavra que condiz com o início da letra sorteada. Quando alguém conclui suas repostas ou dentro de um tempo estipulado descreve o número mínimo de respostas ao questionário e exclama 'Stop', todos os demais param e é feita uma contagem dos pontos de cada um dos participantes. Todos leem suas respostas em cada coluna correspondente a uma rodada. Ao término de cada rodada quem gritar stop marca 8 pontos e um ponto referente a cada resposta dada. Após, sorteia-se outra letra e segue o jogo. No final somam-se os pontos e o vencedor da primeira etapa ganha uma prenda e passa a comandar o jogo. Na repescagem todos têm uma segunda chance de terminar as respostas (Atividades Cras, s. d.). Pode ser incrementadas variações no modo de jogar e marcar os pontos.

Desta forma, pode-se perceber que as atividades socioeducativas empreendidas no projeto de extensão e exemplificadas neste texto, podem permitir o processo de autonomia e autocontrole do sujeito. Para além desses aperfeiçoamentos pessoais, os projetos socioeducativos contribuem na formação à participação e à cidadania, a partir dos interesses, demandas e potencialidades da faixa etária, pautados no fortalecimento de laços e vínculos, o que se verifica a seguir.

\section{Projetos socioeducativos: contribuições no fortalecimento de laços e vínculos}

Quando se realiza um planejamento para desenvolver um determinado projeto primeiramente busca-se avaliar e estudar o público-alvo a ser atingido e beneficiado com o mesmo para, dessa forma, implementar as 
atividades com a intenção de obter êxito. Nesta perspectiva, Stephanou (2003) afirma que os projetos sociais não são realizações isoladas, ou seja, não mudam a realidade sozinhos, pois estão sempre em interação por meio de diferentes modalidades de relação com planos e programas, numa visão mais abrangente da questão social, no âmbito público ou no terceiro setor. Assim, "[...] projetos sociais não existem a partir de si mesmos. Em geral, são construídos a partir de organizações que têm intervenções sociais de maior amplitude do que os próprios projetos" (Stephanou, 2003, p. 25).

Nessa perspectiva, o projeto socioeducativo, a partir de seus facilitadores, mantém uma relação de confiança e de segurança para que as crianças e os adolescentes possam minimizar as suas preocupações e os seus medos, estabelecendo uma aliança. Ressalta-se que os facilitadores necessitam estar preparados sócio emocionalmente para poder subsidiar certos comportamentos, atitudes, e a maneira pela qual os participantes se pronunciam, atuando com estratégias que fortalecem os laços e os vínculos.

Conforme Resolução n 109, do Conselho Nacional de Assistência Social (2009), fortalecimento de laços e vínculos é:

Serviço realizado em grupos, organizado a partir de percursos, de modo a garantir aquisições progressivas aos seus usuários, de acordo com o seu ciclo de vida, a fim de complementar o trabalho social com famílias e prevenir a ocorrência de situações de risco social. Forma de intervenção social planejada que cria situações desafiadoras, estimula e orienta os usuários na construção e reconstrução de suas histórias e vivências individuais e coletivas, na família e no território. Organizase de modo a ampliar trocas culturais e de vivências, desenvolver o sentimento de pertença e de identidade, fortalecer vínculos familiares e incentivar a socialização e a convivência comunitária. Possui caráter preventivo e proativo, pautado na defesa e afirmação dos direitos e no desenvolvimento de capacidades e potencialidades, com vistas ao alcance de alternativas emancipatórias para o enfrentamento da vulnerabilidade social.

O fortalecimento de laços e vínculos possui caráter preventivo, pautado na defesa dos direitos e no desenvolvimento das capacidades e potencialidades de cada indivíduo, bem como precavendo situações de vulnerabilidade (Secretaria Nacional de Assistência Social, 2017). A vulnerabilidade é uma junção entre diversos fatores, dentre estes econômicos, sociais, ambientais, fisiológicos, psicológicos e legais. Vignoli (2006) chama atenção para alguns aspectos, que são destacados para informar o determinante de vulnerabilidade social: ciclo de vida (algumas etapas do ciclo de vida são mais vulneráveis); crise econômica e desastres ambientais; incerteza, insegurança e rupturas da complexidade da vida social da modernidade avançada; desproteção em decorrência da erosão do estado e da família; carência pela desatualização ou imobilidade de capital físico, humano e social, associado à incapacidade de influenciar decisões que distribuem recursos; dinamismo das condições de pobreza (os fatores que determinam uma receita pequena e persistente).

Para fortalecer e encorajar as crianças e os adolescentes, é necessário que sejam realizados encontros buscando: ampliar as formas de ensinar, agir e pensar; alocar o fundamento da convivência grupal; e despertar emoções que não estão dadas, não são passivas e não são pré-definidas, já que as mesmas são produzidas pelas crianças e adolescentes nos encontros, e são direcionadas aos objetivos que gostariam de atingir.

[...] estudos reposicionam a questão das emoções tanto nos estudos acadêmicos quanto na orientação programática de políticas sociais, visto que estabelece outros nexos entre ação e razão, bem como buscam superar os modismos nos quais a emoção é entendida como uma força interior que a partir do auto-esforço, da auto ajuda o indivíduo modifica ou supera. Há uma supervalorização do prefixo "auto", que no limite torna-se uma ação disciplinadora e que responsabiliza o indivíduo e o convoca a ser feliz, bem humorado e conformado (Sawaia, 2003, p. 29). 
Com essa preocupação de proporcionar o fortalecimento de laços e vínculos, as atividades socioeducativas extensionistas são planejadas e se materializam por meio dos grupos, estimulando e orientando as crianças e os adolescentes na construção e reconstrução de suas histórias e vivências individuais e coletivas, na família e no território. Assim, as ações desenvolvidas no projeto de extensão até o momento criaram situações de convivência para a realização de diálogos e enfrentamento de vulnerabilidades, e também para a construção de alternativas. Trabalhou-se a valorização e o reconhecimento, a escuta, a produção coletiva, o exercício de escolhas, a tomada de decisão sobre a própria vida e de seu grupo, o diálogo, o reconhecimento de limites e de possibilidades das situações vividas, as experiências de escolha e de decisão coletivas, o aprendizado e o ensino de forma igualitária, o reconhecimento e a nomeação das emoções nas situações vividas, o reconhecimento e a admiração da diferença, entre outros resultados.

Dessa forma, a partir das reflexões empreendidas, compreendeu-se que, para quem ministra a ação socioeducativa, o processo formativo é gratificante e construtivo, e para quem participa é transformador, uma vez que auxilia nas relações de vida cotidiana de cada criança e adolescente, estabelecendo uma forma mais tranquila de manter o autocontrole. Entendeu-se que o projeto não é somente execução, já que implica em transformação do sujeito e, por sua vez, do social. Logo, o projeto de extensão se constitui numa importante ferramenta estratégica que, por meio de ações delimitadas, oferece respostas de maneira positiva às manifestações da questão social.

\section{Considerações finais}

Frente às considerações proferidas ao longo do texto, verificou-se que o Lar da Menina já desenvolvia uma série de atividades no intuito de socializar e promover as vivências familiares e comunitárias, assim como o bom relacionamento individual e coletivo. Contudo, a partir do projeto de extensão e de suas atividades socioeducativas, permitiu-se o estabelecimento de uma conexão entre a relação de autoconhecimento e o aprendizado diário de cada criança ou adolescente participante, em sua caminhada pela busca da autonomia, do autocontrole e do fortalecimento de laços e vínculos.

O projeto socioeducativo tem sido uma das maneiras de trabalhar com os participantes sobre as relações interpessoais na vida cotidiana, familiar e comunitária, a partir da relação de confiança estabelecida entre o facilitador e o envolvido no projeto. Ainda, constitui-se em uma alternativa viável e eficaz para a prevenção e superação de situações de vulnerabilidades e risco social.

As maiores dificuldades encontradas na execução do projeto foram as advindas das mais diversas vulnerabilidades, as quais afetam profundamente o desenvolvimento e a maneira de pensar e agir destas crianças e adolescentes. Assim, o projeto socioeducativo de extensão surgiu para suprir essa necessidade e proporcionar um processo de escuta, no qual a confiança entre o facilitador e o participante tornou-se 0 fundamento para se poder trabalhar os entraves e as problemáticas que envolvem os participantes do projeto.

Outro ponto a se mencionar e destacar remete ao processo de formação continuada dos participantes. Constatou-se pelas reflexões que, para quem auxilia no desenvolvimento de projetos socioeducativos, tem sido uma experiência transformadora e de construção de conhecimento, além de proporcionar o desenvolvimento da prática docente, da familiarização com o ambiente em sala de aula e com estratégias de trabalho pedagógico. Outrossim, reforçou que as ações socioeducativas extensionistas facilitam a capacidade de atuar em trabalhos de grupos, a partir do respeito e da ajuda mútua.

Por fim, salienta-se a necessidade de mais discussões acerca desse assunto. Nesse recorte textual, abordou-se uma vivência particular e os seus processos, mediado por um arcabouço teórico. Contudo, acredita-se que realizar um levantamento acerca dos projetos socioeducativos que estão sendo desenvolvidos em ONG, 
identificando características e ações de sucesso, pode ser ampliado, de modo a promover uma complementação aos resultados positivos dessa investigação.

\section{Agradecimentos}

À Pró-Reitoria de Extensão do Instituto Federal de Educação, Ciência e Tecnologia do Rio Grande do Sul, pelo financiamento desse estudo. Ao Lar da Menina de Getúlio Vargas/RS pela parceria.

\section{Contribuição de cada autor}

A autora A.P.F.M. participou no desenvolvimento do projeto, de todas as etapas da pesquisa: metodologia do projeto, revisão da literatura e escrita do artigo; a A.S.C. participou como coordenadora do projeto de extensão, realização das diferentes etapas da proposta extensionista, orientação das estudantes, revisão intelectual crítica do artigo e redação final.

\section{Referências}

Armani, D. (2004). Como elaborar projetos? Guia prático para elaboração e gestão de projetos sociais. Porto Alegre: Tomo Editorial.

Atividades Cras. (s. d.) Atividades e Dinâmicas Organizadas em Percursos para uso dos Serviços do CRAS. Recuperado de: http://atividadescras.blogspot.com/?view=sidebar

Campos, G. W., \& Campos, R. T. O. (2006). Co-construção de autonomia: O sujeito em questão. In G. W. Campos, \& M. C. De Souza Minayo (Eds.), Tratado de Saúde Coletiva. (pp. 669-688). São Paulo: HUCITEC, Rio de Janeiro: FIOCRUZ.

Carvalho, I. C. M., Müller, L. H., \& Stephanou, L. (2003). Guia para elaboração de projetos sociais. 2 ed. São Leopoldo: Sinodal.

Carvalho, M. C. B., \& Azevedo, M. J. (2005). Ações socioeducativas no âmbito das políticas públicas. In Centro de Estudos e Pesquisas em Educação, Avaliação: Construindo parâmetros das ações socioeducativas. (pp. 25-33). São Paulo: CENPEC.

Castaman, A. S. (2019). Práticas educativas: Fortalecimento de laços afetivos entre os usuários participantes do Lar da Menina de Getúlio Vargas. Sertão: Instituto Federal de Educação, Ciência e Tecnologia do Rio Grande do Sul - Campus Sertão. (Mimeo).

Conselho Nacional de Assistência Social - CNAS (2009). Resolução no 109, de 11 de novembro de 2009. Aprova a Tipificação Nacional de Serviços Socioassistenciais. Recuperado de: http://www.mds.gov.br/cnas/ legislacao/resolucoes/arquivos-2009/cnas-2009-109-11-11-2009.pdf/view

Costa, A. C. G. (2006). Por uma política de execução das medidas socioeducativas: Conceitos e Princípios norteadores. Brasília: Secretaria Especial dos Direitos Humanos.

Freire, P. (2002). Pedagogia da autonomia: Saberes necessários à prática educativa. Rio de Janeiro: Paz e Terra.

Landim, L. (1998). Ações em sociedade - Militância, caridade, assistência, etc. Rio de Janeiro: NAU - Instituto de estudos da religião (ISER).

Landim, L. (2002). “Experiência militante”: histórias das assim chamadas ONGs. Lusotopie, 1, 215-239. Recuperado de: http://www.lusotopie.sciencespobordeaux.fr/landim.pdf

Lar da Menina. (2019). Ação Social Getuliense Nossa Senhor da Salete - Lar da Menina. Recuperado de: http://lardameninadegetulio.blogspot.com/2011/08/inclusao-digital.html

Portal da Educação. (s. d.) Técnicas de Dinâmicas de Grupo. Disponível em: https://siteantigo.portaleducacao.com.br/ conteudo/artigos/administracao/tecnicas-de-dinamicas-de-grupos/21458.

Prieto, M. (2007). La dramatización: Una técnica lúdica de aprendizaje. Boletín de ASELE, 36, 11-25. 
Sanglard, G. (2003). Filantropia e Assistencialismo no Brasil. História, Ciências, Saúde, 10, 1095-1098.

Sawaia, B. (2009). Psicologia e desigualdade social: Uma reflexão sobre liberdade e transformação social. Revista Psicologia \& Sociedade, 21(3), 364- 372.

Secretaria Nacional de Assistência Social-SNAS. (2017). D. Perguntas Frequentes: Serviço de Convivência e Fortalecimento de Vínculos (SCFV). Brasília: Ministério do Desenvolvimento Social e Combate à Fome (MDS). Recuperado de: http://www.mds.gov.br/webarquivos/publicacao/assistencia social/perguntas e respostas/ PerguntasFrequentesSCFV 032017.pdf

Silveira, R. V. (2006). Constituição jurídica das ONG's. Recuperado de: https://www.univates.br/ media/graduacao/direito/CONSTITUICAO JURIDICA DAS ORGANIZACOES.pdf

Stephanou, L., Muller, L. H., \& Carvalho, I. C. M. (2003). Guia para elaboração de projetos sociais. Porto Alegre: Fundação Luterana.

Tachizawa, T. (2004). Organizações não governamentais e terceiro setor: Criação de ONGs e estratégias de atuação. 2 ed. São Paulo: Atlas.

Vignoli, J. R. (2006). Vulnerabilidade sociodemográfica: Antigos e novos riscos para a América Latina e o Caribe. In J. M. P. Cunha (Org.), Novas Metrópoles Paulistas: População, vulnerabilidade e segregação. (pp. 95-142). Campinas: UNICAMP.

Como citar este artigo:

Castaman, A. S., \& Machado, A. P. F. (2020). Um projeto socioeducativo com crianças e jovens do Lar da Menina. Revista Brasileira de Extensão Universitária, 11(2), 125-134. https://periodicos.uffs.edu.br/index.php/RBEU/article/view/ $10878 / \mathrm{pdf}$ 